\title{
Morel's Disease and Caseous Lymphadenitis: a Literature Review with Special Reference to Saudi Arabia
}

\author{
Elhassan M. A. Saeed* and Khalid B. Alharbi \\ Department of Veterinary Medicine, College of Agriculture and Veterinary Medicine, Qassim University, Saudi \\ Arabia
}

\begin{abstract}
Morel's disease (MD), caused by Staphylococcus aureus subspecies anaerobius and caseous lymphadenitis (CLA), caused by Corynebacterium pseudotuberculosis are two of the major constraints of sheep and goats industry. CLA is prevailing in most parts of the world including USA and Europe, while MD is prevailing in some African and Asian countries including Kingdom of Saudi Arabia (KSA), plus some reports of outbreaks in some European countries. In spite of some differences in epidemiology and characteristics of abscesses in the two diseases and easy microscopic differentiation, MD is greatly misdiagnosed as CLA in KSA and elsewhere. Chronic and generally subclinical and contagious nature of infections and in-efficiency of drug therapy besides poor response to available vaccines which are targeting only CLA make the control difficult and prevalence high. This article reviews the main features of epidemiology, virulence factors, clinical manifestations, diagnosis and control measures of these two diseases. It is intended to display the differences between the two diseases and that the MD is at least should have the same importance as CLA in KSA; and to ensure the importance of development of a bivalent vaccine. Quality of the putative vaccine is discussed here. This review is the first for MD and for MD and CLA together.
\end{abstract}

Keywords: Abscess disease, bivalent vaccine, caseous lymphadenitis, Morel's disease, Saudi Arabia.

\section{Introduction}

Morel's disease (abscess disease) and caseous lymphadenitis (pseudotuberculosis) are non-fatal, contagious diseases of sheep and goats as primary hosts; and some other animals as well as humans can serve as secondary hosts [1,2]. Morel's disease (MD) is caused by Staphylococcus aureus subsp. anaerobius and caseous lymphadenitis (CLA) is caused by Corynebacterium pseudotuberculosis. The two diseases are endemic in nature with high morbidity rate and frequent recovery. Once introduced into a flock, they are very difficult to control because of their poor response to treatment, their ability to persist in the environment and the limitations in detecting sub-clinically infected animals $[1,3,4]$. MD having much shorter (2-3 weeks) incubation period compared to CLA (2-6 months) [1] and faster growth of causative agent is expected to be more endemic and outbreaks faster.

Caseous lymphadenitis has a worldwide distribution and high prevalences [5]. However, MD has much less reported distribution and prevalences; it occurs mainly in Africa and Asia, including KSA [6, 7, 8]; in addition to a few reports of outbreaks in Europe $[9,10,11]$. The two diseases have more or less similar clinical manifestations; they are characterized by abscess formation adjacent to or inside lymph nodes. In MD, abscesses are formed near [1] or inside [12] superficial lymph nodes, while in CLA abscesses are formed only inside both superficial and visceral lymph nodes [5]. In the visceral form of CLA there are systemic complications that can lead to chronic thinning [13]. Besides location of abscesses, there are some epidemiological and clinical differences between the two diseases that are enough to differentiate between them $[1,4,5,13)$.

Considerable economic losses due to these two diseases, particularly in sheep and goats industry are reported from countries where they prevail $[1,3,14,15$,$] . Losses are caused by condemnation and downgrading$ of carcasses and skin in abattoirs as well as reduction in reproductive efficiency, wool growth, meat and milk production. In Saudi Arabia, which is a big small ruminant market to many neighboring and remote countries, abscess diseases (MD and CLA) are adversely affecting the development of sheep industry [16].

There is no available vaccine that is known to confer solid immunity against MD and/or CLA [17, 18, $19]$ and that an effective vaccine against the two diseases is an urgent and real need.

The aim of this article is to review the main aspects of MD and CLA including epidemiology, virulence factors, clinical manifestations, diagnosis and control measures with special emphasis on Saudi Arabia. Major points to differentiate between the two diseases and characteristics of the missing efficient bivalent vaccine are of most concern. 
2.1 Distribution and host range

\section{Epidemiology Of Md And Cla}

CLA is distributed in most parts of the world; it is found in North and South America, Australia, New Zealand, Europe, Asia and Africa [5], with high prevalences. However, MD has much less reported distribution in spite of its early description by Morel in 1911 in France; it occurs mostly in Africa and Asia. So far, it has been reported in Kenya [6], Somalia [20], the Sudan [7], Saudi Arabia [8] and Tunisia [21]. Only a few outbreaks have been reported in Europe: Hungary [9], Spain [10], Denmark [22], Croatia [23] and Poland [11].

CLA affects mainly sheep and goats, though it can also infect cattle and horses [13], and rarely, humans [2]. The pathogen has been isolated from other species, including pigs, buffaloes, deers, porcupines, llamas, camels and laboratory animals [3,5]. Besides Cps, CLA in camels (young) is also caused by Corynebacterium ulcerans [24]. Sheep and goats are also the main hosts of MD [9, 8, 25, 26]. Saan infection was also reported in one case of a dog [27] and a few human cases [28, 29, 30, 31].

\subsection{Nature, risk factors, prevalence and economic impact}

The two diseases are endemic and contagious in nature. They are non-fatal chronic or subclinical with high morbidity rate and frequent relapses $[4,9,13]$. MD is mainly encountered in young animals within the first 4-10 months of life [32], while CLA is mainly in adult animals and is found increasing with age [33]. Unlike CLA, MD was found associated with fattening; incidence was found to be higher in feedlot areas $(62.5 \%)$ compared to natural grazing areas (5.8\%) [34]. Some sheep breeds were found to be more susceptible to the disease than others $[16,35]$. Males of both sheep and goats had the highest rate of infection compared to females $(\mathrm{p}<0.01)[16]$.

The economic impact of CLA and MD in the world in general and in Saudi Arabia can be estimated by the level of prevalences of these diseases. Prevalences of CLA as high as 61\% were found in Australia [36]; 43\% have been estimated in USA [37]; 21-36\% in Canada [38]; 45\% of sheep flocks in the UK have abscesses [39], more than 30\% in Brazil [13]. In Saudi Arabia, the prevalence of abscess disease (MD and CLA) was reported varied between 5\%-44.1\% in sheep farms, and between $2.2 \%-6.5 \%$ in goat farms [16]. Reports on prevalence of MD are few. In an outbreak of MD in a flock of goats in KSA, 61 out of 165 goats showed abscesses in various body lymph nodes [8]. Saudi Arabia has around 17,000,000 heads of sheep and goats and it is a big sheep and goats market for some neighboring and remote countries, but due to scarcity of research and misdiagnosis, prevalence of and economic impact of MD is unknown but expected high. Musa et al. [4] reported an isolation rate of $44 \%$ of Saan from pus samples $(n=136)$ obtained from sheep carcasses in the Sudan, while Cps was isolated from 33\%. A prevalence of $93.6 \%$ was reported in a goat flock in Poland [1]. The economic losses include carcass condemnation, decreased milk production, decreased weight gain, reduced value of skins due to scarring, and the cost of the drugs and labor needed to treat superficial abscesses. Losses are increased when the affected lymph nodes are in critical areas (jaw, crural region, udder); negatively affecting chewing and locomotion. Economic losses due these diseases have not yet been computed.

\subsection{Zoonotic potential}

Cps is considered an emergent public health problem. This bacterium can produce diphtheria toxin. This has been clearly demonstrated in vitro [40] and has led authorities from many countries to urge their health services to be aware of diseases caused by all the diphtheria toxin-producing species of Corynebacterium, including Cps and C. ulcerans, in the differential diagnosis of diphtheria. For many years, the identification of any toxigenic C. pseudotuberculosis required notification to communicable disease control agencies [41]. Recently, a human case of toxigenic C. pseudotuberculosis was reported [42]. In addition to the production of diphtheria toxin by lysogenic Cps, common strains can infect humans and cause suppurative lymphadenopathy; these events are traditionally associated with farm animal contact and contaminated dairy products. About 33 human cases were reported from different countries, especially from Australia [2].

Cases of Saan infection in humans are very few [28, 29, 30, 31]. The first report of Saan from a human was in a patient presenting with septicemia, septic arthritis, and multiple pulmonary abscesses [31]. It is believed that the cases in humans are much underestimated.

\subsection{Sources of infection and transmission}

The main source of infection in both MD and CLA is infected animals, with or without clinical symptoms; these animals contaminate the soil, water, feed, pastures and facilities with pus from abscesses that drain spontaneously and from nasal secretions and feces in case of CLA. Transmission can occur through direct or indirect contact or through wounds that come into contact with pus from the abscesses of sick animals [43]. Materials that are used in the management of the animals, such as during castration, identification with ear tags or by tattooing, contact with an uncauterized umbilical stump, and drainage of abscesses, can transmit the agents. The use of barbed-wire fences or troughs and posts with sharp, cutting edges can cause lesions in the 
skin of the animals, opening passage for the entry of bacteria [44]. Immersion baths immediately after shearing can disseminate the infectious agent, because these solutions can harbor bacteria for up to $24 \mathrm{~h}$ [45]. Vectors such as insects (especially flies) should be considered in the transmission of the disease, since $\mathrm{C}$. pseudotuberculosis has been isolated from the bodies of domestic flies (mechanical vector) and from fly intestines and feces (biological vector). Saan is not pathogenic by the oral route [46], but Cps can cause the disease by oral route [47].

\subsection{Pathogenicity}

These two abscess conditions are essentially an acute to subacute cellulitis characterized by the development of subcutaneous abscesses at the vicinity of or inside lymph nodes [1, 48]. The inflammatory process leads to liquefactive necrosis of the affected lymph node due to the secretion of an alpha haemolysin by the organisms. Alpha haemolysin is lytic to erythrocytes, dermo-necrotic, lethal and exhibits a wide variety of other biological properties $[49,50]$.

\subsection{Characterization of the etiological agents}

2.6.1 Microscopic, cultural and biochemical characteristics

2.6.1.1 Corynebacterium pseudotuberculosis (Cps)

The general characteristics of Cps were reviewed by Guimarães et al. [1] and Bastos et al. [2]. The genus Corynebacterium belongs to the Actinomycetes group, which also includes the genera Mycobacterium, Nocardia and Rhodococcus [5]. This bacterium was first described in 1888 by Nocard, in a case of lymphangitis in cattle and it was known as C. ovis. It is Gram-positive rods, facultative intracellular pathogen that displays pleomorphic forms, ranging from coccoid to filamentous rods, grouped in parallel cells or in a format similar to Chinese letters and measures approximately $0.5-0.6 \mu \mathrm{m}$ in width and 1.0-3.0 $\mu \mathrm{m}$ in length [13]. These bacteria do not have a capsule or flagella and they do not sporulate; however, fimbriae are present [51]; and its optimum growth conditions are at $37^{\circ} \mathrm{C}$ with $\mathrm{pH}$ values ranging between 7.0 and 7.2 [52]. It grows well on enriched media such as blood agar, brain heart infusion (BHI) agar or broth or enriched medium with animal serum. Its cultivation improves when BHI is complemented with yeast extract, tryptone or lactalbumin [53]. Its growth in a solid culture medium is initially sparse on an agar surface and then becomes organized in clumps or in palisades, taking on a cream to yellowish coloration. Colonies are dry, opaque and concentrically ringed, and after several days of incubation can reach $3 \mathrm{~mm}$ in diameter and when grown in blood agar, it is possible to detect betahemolysis after a period of 48 to $72 \mathrm{~h}$ of incubation [54].

Biochemically, Cps is characterized by the production of catalase, phospholipase D, and urease, and by the fermentation of carbohydrates such as maltose, mannose, glucose, and galactose [52]. It does not perform lactose fermentation or gas production [55]. It has no proteolytic activity, does not have the ability to hydrolyze gelatin or digest casein and is oxidase negative [52]. It comprises two biotypes based on the production of nitrate reductase. Strains that reduce nitrate to nitrite infect mainly horses (biovar equi) and are sensitive to streptomycin, while the strains that infect goats and sheep (biovar ovis) are mainly nitrate negative and resistant to streptomycin [56]. Cattle are infected by both reducing and non-reducing nitrate strains [57].

\subsubsection{Staphylococcus aureus subsp. anaerobius (Saan)}

This bacterium was firstly isolated in 1920 [58] and described by de la Fuente et al. [25]; and recently, Szalus-Jordanow et al. [59] has studied the phenotypic and genotypic properties of Saan isolated from lymph node abscesses of goats. It is closely related to other Staphylococcus aureus organisms. It is Gram-positive cocci, measuring 0.8 to $1.0 \mu$, arranged in pairs, tetrads and clusters, non-motile and non-spore-forming. On the primary isolation medium, growth is obtained only in media supplemented with blood, serum, or egg yolk and incubated microaerobically or anaerobically at 30 to $40^{\circ} \mathrm{C}$. Colonies on blood agar after 2 days of incubation are very small (1 to $3 \mathrm{~mm}$ in diameter), low convex, circular, entire, smooth, glistening, opaque and ${ }_{\beta}$-hemolytic and produce no pigment. Luxuriant growth is obtained on Dorset egg medium, with colony diameters of 4 to $6 \mathrm{~mm}$. In broth cultures (3 days), a white granular deposit without turbidity is formed. When broth media are supplemented with 5\% serum, the typical deposit appears after $24 \mathrm{~h}$. All strains grow well at $\mathrm{NaCl}$ concentrations up to $10 \%$ [25].

Unlike other staphylococci, Saan is catalase and benzidine negative. It produces coagulase and does not ferment mannitol, reduces nitrates, or produces acetylmethylcarbinol. It produces acid from glucose, fructose, maltose, and sucrose. They are hyaluronidase positive and staphylokinase negative. Saan is easily differentiated from S. saccharolyticus (anaerobic) by colonial morphology, catalase activity, the benzidine test, coagulase and thermonuclease production, and hemolytic activity. 
2.6.2 Variability and virulence factors

2.6.2.1 Cps

Compared to other pathogenic bacteria, few studies have investigated the antigens and virulence determinants of Cps. Two virulence determinants have been well characterized: the exotoxin PLD (phospholipase D) and the toxic lipid cell wall. This exotoxin works as a permeability factor that promotes the dissemination of the pathogen from the initial site of infection to all the body tissues of the host. Additionally, PLD causes the dermonecrosis of endothelial cells, which contributes to the passage of Cps from the dermis to small blood vessels, thereby gaining access to lymphatic vessels [60]. Further, PLD is considered a cytotoxic exotoxin for white blood cells, as it promotes the destruction of goat macrophages during experimental infection [61]. Cps multiplying within macrophages and surviving the action of phagolysosomic enzymes, because of the external lipid layer of the cell wall [5]. After getting into the host, the agent disseminates freely or within macrophages, mainly through the afferent lymphatic system, to local lymph nodes and internal organs. This process depends on the ability of the agent to infect macrophages, resist phagolysosomes and kill cells, liberating new bacteria and causing necrosis [62]. Other genes such as CP40 and fag A, B, C and D, were described and shown to have an important role in the virulence of Cps [63]. Various molecular techniques have been used to type $\mathrm{C}$. pseudotuberculosis. The two techniques that have given promising results for typing $\mathrm{C}$. pseudotuberculosis strains are PFGE (pulsed-field gel electrophoresis) [64] and RAPD (randomly amplified DNA polymorphisms) [65].

\subsubsection{Saan}

Saan is reported existing as a single bacterial clone worldwide $[12,59,61]$. In the study conducted by Szalus-Jordanow [59], 20 staphylococci isolated from lymph node abscesses of 19 goats of two herds were identified as Saan. All of the strains grew under microaerobic conditions, negative in the catalase test, showed the typical phenotypic properties of S. aureus and were genotypically be identified by a positive sa442, 235 rDNA, nuc, coa and spa PCR reaction. The variable regions of the coa and spa gene of the 20 strains appeared with uniform amplicon sizes. Amplification and sequencing of kat gene of a single Saan strain and a reference strain of Saan (DSM 20714) revealed a complete identity of the kat sequences of both strains and a katB sequence obtained from GenBank (AJ000471). In the study done by de la Fuente et al. [12], molecular analysis including pulsed-field gel electrophoresis (PFGE), multilocus sequence typing (MLST) and accessory gene regulator (agr) typing was carried out on 94 Saan strains isolated in different countries. All of the 94 Saan isolates examined belonged to one PFGE type. Representative isolates of all PFGE subtypes as well of all countries belonged to the same sequence type (ST), ST1464, which was a singleton, and to the agr type II. Further, Elbir et al. [66] has also reported that 17 Saan isolates were shown to have the same phenotypic and genotypic characteristics. It is well known that S. aureus produces many virulence factors, such as hemolysins, leukocidins, proteases, enterotoxins, exfoliative toxins, and immune-modulatory factors [67]. The agr system, known as the quorum-sensing system, is known to play a central role in the regulation of virulence factors [68].

\subsubsection{Resistance}

2.6.3.1 Cps

Through experimental contaminations of soil and of sheep and goat facilities, it was found that $\mathrm{Cps}$ can survive up to eight months at various temperatures [69]. In bedding straw, it can remain viable for three weeks, during two months in hay, four months in shearing stalls and for more than eight months in the soil. Cps is sensitive to common disinfectants [70] and antibiotics.

\subsubsection{Saan}

Literature on resistance of Saan is very scarce. The strains are very susceptible to lysostaphin and many antibiotics and resistant to lysozyme [25].

\subsection{CLA}

\section{Clinical Signs}

Caseous lymphadenitis in its superficial form is characterized by infection and abscess formation of external lymph nodes, such as the submandibular, parotid, pre-scapular, subiliac, popliteal and supramammary lymph nodes, while the visceral form is characterized by abscessing of internal organs, such as lungs, liver, kidneys, uterus, spleen and internal lymph nodes, such as the mediastinal and bronchial lymph nodes. These two forms can coexist; however, other less common sites can be involved, such as mammary gland, scrotum, the central nervous system and joints [13]. Internal abscesses are normally associated with weight loss and weakness, known in sheep as thin-ewe syndrome. The mature abscesses easily leak through fistulas, releasing purulent whitish green discharges into the environment or into the affected organ. The incubation period was estimated at 2-6 months [1]. Abscesses usually recur, months or years later, in the same animal, due to the 
failure to eliminate the infection [3]. In some cases, clinical signs are not distinct, and a post-mortem examination becomes necessary for diagnosis; this makes it difficult to obtain objective data about disease prevalence [71]. The visceral form being more frequent among sheep and the superficial form among goats [72]. External abscesses in the lymph nodes of the head and neck are more common in goats, while the subiliac and pre-scapular lymph nodes are more commonly affected in sheep [69].

\subsection{MD}

Clinical manifestations of MD are confined to abscesses located near or in major superficial lymph nodes, mostly in head and neck regions. Most frequently located in the lymph nodes of the mandibular region (mandibular, parotid and lateral retropharyngeal), followed by superficial cervical, subiliac and popliteal nodes, in that order of frequency [1,25]. The incubation period was estimated at 3 weeks [1]. Clinical signs of MD occur mainly in young animals within the first 6 months of life [32]. However, they were seen both in young and adult goats, but occur more frequently in young goats and are located near, not inside, the lymph nodes [1]. Abscesses tend to persist for 1 to 5 months, then rupture and heal completely. The disease spreads rapidly and its prevalence may approach $100 \%$ in the herd in a few weeks. Szalus-Jordanow et al. [1] reported a prevalence of $93.6 \%$ within 2 months of onset of the disease and dropped to approximately $20-30 \%$ during the following 3 months in one herd and $84.4 \%$ which dropped to about $10-20 \%$ within $3-4$ months in a second herd and the number of abscesses is reduced from 7 to single abscess, mainly in young animals.

Abscesses of MD are round or oval with diameter of $4-10 \mathrm{~cm}$, but may reach $70 \mathrm{~cm}$ [8], soft in consistency when palpated. The contents of almost all abscesses are odourless, viscid, yellowish white to creamy in colour and enclosed in a thick connective tissue capsule [4].

\section{Epidemiological And Clinical Differences Between The Two Diseases}

Differentiation between the two diseases is based on many factors including age and nutritional status of the animal, incubation period and spreading rate, location, size, texture and colour of the abscess and abscess association with lymph nodes. MD is normally affects young ages (4-10 months) [12], while CLA is mainly in adult animals and is found increasing with age [33]. Unlike CLA, MD was found associated with fattening [12]; incidence was found to be higher in feedlot areas (62.5\%) compared to natural grazing areas (5.8\%) [34]. The incubation period of MD was estimated at 3 weeks compared with 2-6 months for CLA [1]. Due to this shorter incubation period and known faster growth of Saan, MD is spreading faster. The sheep abscess contents of CLA have a laminar form when cut, similar to the layers of an onion, caused by the formation of layers of fibrous tissue and thick caseous material or may be calcified, easy to be grasped and hard, while abscesses in goats have a thin and pasty exudates [69]. However, onion-like abscesses were not always present in sheep. It is possible that older abscesses become more consistent, with a tendency towards fibrosis and calcification, progressing to an onion-like appearance, independent of animal species. However, abscess in MD never has the laminar form, caseation or calcification but is always soft in consistency when palpated and may reach $70 \mathrm{~cm}$ in diameter [8] due to faster growth and more spreading ability of its agent. No visceral form of MD as in CLD and no wasting is seen on affected animals. MD abscesses are near and not inside lymph nodes [1], although some reports indicating their presence inside lymph nodes [25]. In MD, abscesses tend to occur anywhere irrespective of lymph nodes location. Abscess colour is white to creamy in MD [4] versus yellowish green in CLA. In addition, microscopic and cultural differentiation of the two agents in pus material is easy; MD agent is cocci in clusters and cannot grow in air, while CLA agent is rods and aerobic.

\section{Immunopathogenesis Of Md And Cla}

Immunopathogenesis of CLA was reviewed by Bastos et al. [2]. The progression of CLA in sheep and goats starts as primary wound infection, with lymphatic and hematogenous dissemination, followed by secondary infection of the lymph nodes and various visceral organs. This is followed by the elimination or containment of infection, the latter presenting as characteristic caseous lesions. The steps of infection have been separated into the following phases: an initial phase (day 1-4 p.i.), characterized by the recruitment of neutrophils to the inoculation site and the draining of the lymph nodes; an amplification phase (day 5-10 p.i.), characterized by the development of pyogranuloma; and a stabilization phase, characterized by the maturation and persistence of the pyogranuloma [73]. Bacterial factors, including PLD and cytotoxic lipids, contribute to pathogenesis at a local level but have little effect on the systemic disease. Cps can survive within macrophages for more than 48 hours and multiplying leading to phagocyte death. The host attempts to restrain and limit the infection through the formation of pyogranulomas, which are characterized by the encapsulation of the Cps infected cells, constituting an important factor for limiting Cps infection[73].

Literature on immunopathogenesis of MD is limited. The role of humoral immunity in MD is greater than the cellular immunity because Saan mainly lives extracellularly. However, cellular immunity to S. aureus in mice was demonstrated [74]. Significantly increased levels of gamma interferon (IFN- $\gamma$ ) were produced by 
CD4+ $\mathrm{T}$ cells and a significant increase in the percentage of IFN- $\gamma$-producing CD4+ and CD8+ T cells was observed.

\section{Diagnosis}

Abscesses in goats and sheep are very suggestive of either CLA or MD, however bacterial isolation is necessary to identify the causative agent, since other bacteria such as Arcanobacterium pyogenes, S. aureus other than Saan, Actinobacillus licheniformis, Pasteurella multocida, Pseudomonas aeruginosa and Streptococci can be found in abscesses $[16,75]$. In animals with respiratory problems of CLA, a thoracic X-ray can reveal masses in the pulmonary parenchyma and lymph nodes [13]. The isolation and identification of Cps and Saan in pus samples by Gram staining, culture and biochemical testing are still the most reliable methods of diagnosis. However, efficient control requires a serological diagnosis because infected animals that have no apparent symptoms, especially in CLA are a source of infection for healthy animals [76]. However, serological diagnosis is not well developed, especially for MD. The detection of specific antibodies to Cps in the serum of animals has been widely promoted throughout the world [77]. Several serological methods have been proposed for the diagnosis of CLA; including complement fixation, immunodiffusion and ELISAs [76, 78, 79]. PCR methods were also used for CLA diagnosis and confirmation [80, 81]. A PCR method presented 94.6\% diagnostic sensitivity. Restriction fragment length polymorphism (RFLP) targeting the PLD gene is also used to confirm identification of Cps [81]. These tests have been reported to be effective in CLA control and eradication programs. Indirect ELISA based on secreted proteins has shown a diagnostic sensitivity and specificity of $93.5 \%$ and $100 \%$, respectively, in the diagnosis of CLD in small ruminants [82]. As Cps is a facultative intracellular pathogen, cell-mediated immunity is an important component of the protective immune response. Thus, a whole-blood IFN- $\gamma$ assay is a promising detection tool for CLA in small ruminant flocks [83, 84, 85]. This method has been optimized, and its ability to correctly detect infected animals has been compared to ELISAs. The sensitivity of IFN- $\gamma$ test was found $89.2 \%$ in experimentally infected goats and the specificity $97.1 \%$, while the sensitivity of a recombinant PLD-based ELISA detected Cps in experimentally infected goats was found $81.0 \%$ and the specificity $97.0 \%$ 84].

\subsection{Differential diagnosis}

The two diseases must be differentiated from each other as each one is the most similar to the other. Pyogranulomatous lesions, such as found in actinobacillosis, tuberculosis and superficial abscesses caused by Arcanobacterium pyogenes and some other pyogenic bacteria, must be differentiated from CLD and MD [16, 72]. The debilitating visceral form of CLD can be clinically similar to chronic parasitism, thinning due to abnormal waste of teeth, alveolar periodontitis, malnutrition and chronic diseases, such as pulmonary adenomatosis, neoplasias and scrapie [72]. In a study conducted by Alharbi (86) in Saudi Arabia to investigate the causes of internal and external abscesses, the bacteria recovered were Staphylococcus aureus, Corynebacterium pseudotuberculosis, Staphylococcus aureus subsp. anaerobicus, Streptococcus spp. and Pseudomonas aeruginosa. This indicates that isolation and identification of abscess-causing bacteria is crucial.

\section{Treatment}

Treatment of abscess affected animals consists of the drainage of abscesses, followed by cleansing and chemical cauterization, usually with $10 \%$ iodine, or even removal of the affected superficial lymph nodes [87]. Although it is an important control measure, this procedure might not be as effective as expected due to the presence of internal abscesses in case of CLD. Drainage of the abscess should be done in a way that avoids environmental contamination, with disinfection of the surgical material before and after the procedure, and all of the disposable materials should be incinerated and buried, including plastics and paper used to cover the area. Also, antibiotic therapy, which is not very efficient in spite of susceptibility of the two agents to many antibiotics in vitro $[25,55]$. The intracellular location of the Cps and the formation of biofilm in natural infections reduces drug efficacy, making antimicrobials inefficient under these conditions [88]. As Saan is mostly an extracellular bacteria, drug efficacy is expected better than in case of Cps. The inefficacy and high cost of antibiotic treatment make it an inviable option for herd-level disease management.

\section{Control And Prevention}

The need for an effective control against CLD and MD is obvious as their incidence is increasing worldwide $[1,19,48]$. As the two diseases have the tendency to spread and persist in herds, in addition to the importation of sheep from countries that are known to have MD and CLA, implementing effective control measures is of high economic importance, especially in Saudi Arabia. An effective program for the control of caseous lymphadenitis should be based on clinical inspection and periodic serology of all animals in the flock, culling the ones that have clinical signs or that are serologically positive. Once infected, an animal hardly eliminates the Cps [89]. Similarly, MD requires both clinical and laboratory measures. The main source of 
infection for a flock is introduction of infected or abscessed animals into a herd, which results in a high frequency of abscesses after two or three years [16]. This stresses the importance of employing biosecurity procedures in all flocks, chiefly during the introduction of animals. Measures designed to reduce the environmental risk of wounding should also be adopted, such as the use of smooth wire fences, troughs and facilities without sharp edges, disinfection of surgical, ear tagging and shearing instruments, systematic use of individual disposable needles, effective control of insects, and disinfection of newborns' navels and any other wounds with 10\% iodine [3]. All control programs should be based on sanitary education of herd owners and technical personnel, otherwise success will be compromised.

Control measures vary with the prevalence of infection. In countries free of these diseases, importation should only be permitted from herds that have been certified free of CLD and MD for three years. All animals should be tested before importing and they should initially be placed in quarantine. In countries with low disease prevalence, the clinically affected animals should be separated and treated or better to be culled, lambs and kids should be reared away from their mothers, and installations and equipment should be well disinfected. In countries with a high incidence of one or both diseases such as in Saudi Arabia, rigorous sanitary measures should be implemented, associated with effective vaccination [19,69]. Once CLA is a chronic disease, the success of a vaccination program can be attributed to the correct use of vaccines and good practices of animal management.

\subsection{CLA}

\section{Vaccination}

Studies have shown that primary infection with viable Cps induces strong protection against subsequent exposures. However, ewes with primary infection remained carriers of the bacterium as a result of primary inoculation [90]. These studies have encouraged scientists to create vaccine model based on the use of killed bacteria [91, 92]. The degrees of protection have varied among these studies, but a common feature is that the protective effects were only partial. The immunogens did not completely prevent the disease, but the clinical course was milder, with significantly lower numbers of granulomas in immunized compared to unvaccinated animals. This effect can greatly decrease the economic losses. Another vaccine model uses the secreted exotoxins of Cps, specifically, PLD has been widely studied, as it is one of the few virulence factors known and is the best characterized protein of Cps. In some studies, the exotoxins are treated with various concentrations of formaldehyde, producing toxoids. These toxoid-based vaccines have shown decreased CLA spread in sheep [93, 94]. Some studies have used a combination of bacterins and toxoids. A product composed of killed Cps and PLD inactivated by formaldehyde was tested in field trials, and the serological results demonstrated the presence of antibodies against PLD as well as against cellular antigens of Cps [94]. In one study, sheep were immunized with a recombinant derivative of PLD, a formalin-killed bacterin, and a bacterin supplemented with recombinant PLD. The combined vaccine provided absolute protection against infection, whereby challenge bacteria were eradicated from all the vaccinated sheep [95]. Subunit vaccine models have also been developed in an attempt to improve the specific immunological response and promote greater rates of protection. Sheep vaccinated twice with $100 \mu \mathrm{g}$ per dose of CP40 in aluminum hydroxide adjuvant were protected against infection with Cps, with an $82 \%$ reduction in the number of infected sheep and a $98 \%$ reduction in lung lesions, suggesting that the 40 $\mathrm{kDa}$ antigen plays a major role in immunity to CLA [96]. Another antigens have been tested but were found with lower effects [97].

A humoral response alone is insufficient to protect the animal, and a good cellular response is not achieved with inactivated vaccines [17]. Studies point to a greater cellular immune response, chiefly a Th1 response, because of the facultative intracellular nature of the microorganism, with production of gammainterferon (IFN- $\gamma$ ) and other cytokines that are important for controlling infection [98]. The role of IFN- $\gamma$ was first demonstrated in experimental infections of mice deficient for the IFN- $\gamma$ receptor with attenuated Cps mutants [99]. Another important cytokine that controls primarily infections by Cps is tumor necrosis factor alpha (TNF-a) [99]. Further, the injection of anti-CD4 or anti-CD8 mAbs also resulted in significantly increased mortality and a marked suppression of IFN- $\gamma$ production but had no effect on TNF-a production [100]. Hence, various attempts have been made to obtain an attenuated live vaccine that is effective against CLA [101, 102]. Experiments with live attenuated bacterial strains as vaccine models have also been performed, but the same pattern of results have been observed: evident humoral induction, varied degrees of immune protection and reduction only in the number of CLA lesions $[103,104]$. So, improvements are still needed to develop a vaccine model for sheep and goats.

\subsection{MD}

Due to the assumption that MD is largely misdiagnosed as CLA [1] and due to its prevalence only in some of the non-developed countries in Africa and Asia, no single commercial vaccine is produced. Vaccine production against MD was considered only in the Sudan, where it is still not commercially available. The first 
trial of vaccination against Morel's disease using formaline- killed bacterin was done by Rodwan [50]. The vaccine reduced the incidence of infection by approximately $65 \%$ and the size of abscess was markedly reduced in lambs which acquired infection in spite of vaccination. Rodwan et al. [105] did a trial using a formalinised killed whole culture, capsular antigen and toxoid, which gave $96.4 \%$ protection. This protection has been achieved both in experimental and field studies. The protective responses were measured by prevention of abscess formation in challenged lambs and monitoring of passive immunity transfer from pregnant ewes to their lambs. The vaccination of ewes before lambing provided passive protection to lambs during the first 20 weeks of age. Elhaj et al. [18] have successfully cultivated Saan in the bioreactor using continuous culture system, which gave good growth with high quality vaccine. The bioreactor culture was inactivated, filtered and used to prepare two types of vaccines with different concentration of cells and toxoid (60\% cells $+40 \%$ toxoid and $50 \%$ cells $+50 \%$ toxoid), which gave $85.8 \%$ and $78.6 \%$ protection, respectively.

In a study conducted by Mahmoud et al. [106], a commercial vaccine (Galnvac 6, CSL Limited) was used in combination with zinc (vaccine alone, zinc alone and both). Concurrent injection of zinc and vaccination gave the longest protection against abscess disease (CLD and/or MD). Alharbi [86] did a similar study with addition of an antiseptic wash to the combination of zinc and vaccination. The combination of the three components gave the best protection. Zinc may improve the immunity and wound healing [107]. However, the use of this combination is less convenient than vaccine alone.

In Saudi Arabia, both diseases are prevailing, but vaccination, which is not widely practiced, is only against CLD using imported vaccines [16]. Due to prevalence of Cps and Saan and their possible coexistence in the same animal [34] and possible presence of some other bacteria [16], these CLA vaccines are poorly protective.

MD and CLA are supposed to be addressed as a one entity problem [16, 22] when considering epidemiological studies. We think this view is accepted only in case of control measures, which are herd management and effective vaccination in both diseases. Basically, "abscess disease" is used for Morel's disease [25], but some people also use it for CLA or for both diseases. It can be proposed here to mean MD and CLA together, especially in countries where both diseases are prevailing such as in KSA, provided that always bearing in mind that it is caused by both Cps and Saan.

\subsection{Features of a putative bivalent effective vaccine}

Due to the clinical similarity between MD and CLA, their possible coexistence in the same animal and equal ability to spread once introduced into a flock in countries where they prevail such as in KSA, it is crucial, convenient and cost-effective to develop a bivalent vaccine. According to the literature cited above, killed bacterial cells plus their toxoids are found most effective against Cps and Saan infections. However, their percentages in the proposed vaccine need to be searched. Live attenuated and subunit vaccines were tried against CLA, but were not found more effective than bacterins plus toxoids. However, research on live attenuated vaccines is still needed to improve the cellular immune response. Origins of bacterial strains are not likely to have effect.

\section{Conclusion}

The present high economic impact of caseous lymphadenitis and Morel's disease in KSA and other countries requires real efforts to combat them through implementation of appropriate biosecurity measures, effective diagnosis and development of an effective vaccine. Due to the high degree of mixing between the two diseases and their co-existence in many areas, a bivalent vaccine is proposed to be developed.

\section{References}

[1] O. Szaluś-Jordanow, J. Kaba, M. Czopowicz, L. Witkowski, M. Nowicki, D. Nowicka, I. Stefańska, M, Rzewuska, M. SobczakFilipiak, M. Binek, and T. Frymus, Epidemiological features of Morel's disease in goats, Pol. J. Vet. Sci. 13(3), 2010, $437-445$.

[2] B. L. Bastos, R. W. Dias Portela, F. A. Dorella, D. Ribeiro, N. Seyffert, et al., Corynebacterium pseudotuberculosis: immunological responses in animal models and zoonotic potential, J. Clin. Cell. Immunol., S4, 005.

[3] L.H. Williamson, Caseous lymphadenitis in small ruminants, Vet. Clin. North Am. Food Anim. Pract., 17, $2001,359-371$.

[4] N.O. Musa, A. Babiker, K. Eltom, K. Rodwan, and S.M. El Sanousi, Prevalence of Staphylococcus aureus subsp. anaerobius in subclinical abscess cases of Sheep. Brit. Microbiol. Res. J.,2(3), 2012, 131-136.

[5] F.A. Dorella, S.C. Oliveira, L.G.C. Pacheco, A. Miyoshi, and V. Azevedo, Corynebacterium pseudotuberculosis: microbiology, biochemical properties, pathogenesis and molecular studies of virulence, Vet. Res. 37, 2006, 201-218.

[6] J.F. Shirlaw, and W.A. Ashford, The occurrence of caseous lymphadenitis and Morel's disease in a sheep flock in Kenya, Vet. Rec. 74, 1962, 1025-1026.

[7] S.M. El Sanousi, A.A. Hamad, and A.A. Gameel, Abscess disease in goats in the Sudan. Rev. Elev. Med. Vet. Pays. Trop. 42, 1989, 379-382.

[8] A. B. Alhendi, S. M. al-Sanousi, Y. A. al-Ghasnawi, and M. Madawi, An outbreak of abscess disease in goats in Saudi Arabia, Zentralbl. Veterinarmed. A., 40, 1993, 646-651.

[9] E. Bajmocy, B. Fazekas, and J. Tanyi, An outbreak of Morel's disease (a contagious sheep disease accompanied by abscess formation) in Hungary, Acta. Vet. Hung., 32, 1984, 9-13. 
[10] J.A. Quiteria, D. Cid, R. Sanz, S. Garcia, and R. de la Fuente, Influence of age of the donor sheep on the phagocytosis of Staphylococcus aureus subspecies anaerobius and S.aureus by neutrophils, Res. Vet. Sci., 61, 1996, 231-233.

[11] J. Kaba, O. Szalus, M. Rzewuska, I. Stefanska, M. Binek, and T. Frymus, An outbreak of Morel's disease in a goat flock (in Polish), Mag. Weter, 16, 2007, 46-48.

[12] R. De la Fuente, C. Balesteros, V. Bautista, A. Medina, J. A. Orden, G. Dominguez- Bernal, and A. Vindel, Staphyloccocus aurus subsp. anaerobius isolates from different countries are clonal in nature, Vet. Microbiol., 150 (1-2), 2010, $198-202$.

[13] A.S. Guimarães, F.B. Carmo, R.B. Pauletti, D. Ribeiro, A.P. Lage, M.B. Heinemann, N. Seyffert, A. Miyoshi, V. Azevedo, and A.M.G. Gouveia, Caseous lymphadenitis: epidemiology, diagnosis, and control, The IIOAB Journal, 2(2), $2011,33-43$.

[14] M.W. Paton, I.R. Rose, R.A. Hart, S.S. Sutherland, A.R. Mercy, T.M. Ellis, and J.A. Dhaliwal, New infection with Corynebacterium pseudotuberculosis reduces Wool production, Aust. Vet. J., 71, 1994, 47-49.

[15] J. Arsenault, C. Girard, P. Dubreuil, D. Daignault, J.R. Galarneau, et al., Prevalence of and carcass condemnation from maedi-visna, paratuberculosis and caseous lymphadenitis in culled sheep from Quebec, Canada, Prev. Vet. Med. 59, $2003,67-81$.

[16] K. B., Al-Harbi, Prevalence and etiology of abscess disease of sheep and goats at Qassim region, Saudi Arabia. Vet. World, 4(11), 2011a, 495-499.

[17] F.A. Dorella, L.G.C. Pacheco, N. Seyffert, et al., Antigens of Corynebacterium pseudotuberculosis and prospects for vaccine development, Exp. Rev. Vac., 8, 2009, 205-213.

[18] M.O. Elhaj, H. Böhnel, and S.M. El Sanousi, Production of abscess (Morel's) disease vaccine by the IBT bioreactor technology, Sudan J. Vet. Res., 24, 2009, 11-15.

[19] K.B. Alharbi, and O. M. Mahmoud, Abscess disease of sheep and goats : A disease of major concern in Saudi Arabia that urges production of an effective vaccine, J. Agric. Vet. Sci., Qassim University, 5 (2), 2012, 61-72.

[20] R.G. Pegram, An unusual form of lymphadenitis in sheep and goats in the Somali Democratic Republic, Trop. Anim. Health Prod. 5, 1973, 35-39.

[21] M.S. Ben Said, H. Ben Maitigue, M. Benzarti, L. Messadi, A. Rejeb, and A. Amara, Epidemiological and clinical studies of ovine caseous lymphadenitis, Arch. Inst. Pasteur Tunis. 79, 2002, 51-57.

[22] K. MØller, J.S. Agerholm, P. Ahrens, N.E. Jensen, and T.K. Nielsen, Abscess disease, caseous lymphadenitis, and pulmonary adenomatosis in imported sheep, J. Vet. Med., 47, 2000, 55-62.

[23] B. Habrun, E. Lestes, G. Kompes, Z. Cvetnic, M. Mitak, (2004): Caseous lymphadenitis in goats and sheep, Vet. Stanica. 35, 2011, $139-144$.

[24] M.T. Tejedor, J. L. Martin, P. Lupiola, and C. Gutierrez, Caseous lymphadenitis caused by Corynebacterium ulcerans in the dromedary camel, Can. Vet. J., 41(2), 2000, 126-127.

[25] R. De la Fuente, G. Suarez, K. H. Schleifer, Staphylococcus aureus subsp. anaerobius subsp. nov., the causal agent of abscess disease of sheep, Internat. J. Syst. Bact., 1985, 99-102.

[26] R. Sanz, I. Marin, J.A. Ruiz-Santa-Quiteria, J.A. Orden, D. Cid, R.M. Diez, K.S. Silhadi, R. Amils, and R. de la Fuente, Catalase deficiency in Staphylococcus aureus subsp. anaerobiusis associated with natural loss-of-function mutations within the structural gene, Microbiol. 146, 2000, 465-475.

[27] C. Oliveira, C. A. Lopes Leite, R. Sfmia, and C.M. Barreto, Etiology of canine otitis media and antimicrobial susceptibility of coagulase-positive Staphylococci in Fortaleza City, Brazil, Braz. J. Microbiol. 37, 2006, 144-147.

[28] P. A. Crawford, M. F. Hand, S. J. Richards, and R. G. Masterton, Septicaemia caused by a catalase-negative Staphylococcus aureus, J. Hosp. Infect., 27, 1994, 320-322.

[29] U. Over, Y. Tuc, and G. Soyletir, Catalase-negative Staphylococcus aureus: a rare isolate of human infection, Clin. Microbiol. Infect. 6, 2000, 681-682.

[30] B. Friedberg, E. Hauer, M. Belkhirat, J. Watine, and A. Le Coustumier, Catalase-negative Staphylococcus aureus: a rare cause of catheter-related bacteremia, Clin. Microbiol. Infect., 9, 2003, 1253-1255.

[31] S.L. Peake, J.V. Peter, L. Chan, R.P. Wise, A.R. Butcher, and D.I. Grove, First report of septicemia caused by an obligately anaerobic Staphylococcus aureus infection in a human, J. Clin. Microbiol. 44, 2006, 2311-2313.

[32] R. De la Fuente, D. Cid, R. Sanz, J.A. Ruiz-Santa-Quiteria, An outbreak of abscess disease associated with shearing, Small Rumin. Res., 26, 1997, 283-286.

[33] F.R. Zavoshti, A.B.S. Khoojine, J.A. Helan, B. Hassanzadeh, and A.A. Heydari, Frequency of caseous lymphadenitis (CLA) in sheep slaughtered in an abattoir in Tabriz: comparison of bacterial culture and pathological study, Comp. Clin. Pathol., 21, 2012, $667-671$.

[34] A. Babiker, and S. El Sanousi, Effects of fattening on the occurrence of sheep abscess disease (Morel's disease), Deutscher Tropentag, October 5-7, 2004, Berlin.

[35] M. Pepin, P. Pardon, and F. Lantier, Corynebacterium pseudotuberculosis infection in adult ewes by inoculation in the external ear, Am. J. Vet. Res., 49, 1988, 459-463.

[36] M.J. Middleton, V.M. Epstein, and G.G. Gregory, Caseous lymphadenitis on Flanders Island: prevalence and management surveys, Aust. Vet. J., 68, 1991, 311-312.

[37] S.G. Stoops, H.W. Renshaw, and J.P. Thilsted, Ovine caseous lymphadenitis: disease prevalence, lesion distribution, and thoracic manifestations in a population of mature culled sheep from western United States, Am. J. Vet. Res., 45, $1984,557-561$.

[38] J. Arsenault, C. Girard, P. Dubreuil, D. Daignault, J.R. Galarneau, et al., Prevalence of and carcass condemnation from maedi-visna, paratuberculosis and caseous lymphadenitis in culled sheep from Quebec, Canada, Prev. Vet. Med. 59, $2003,67-81$.

[39] S.H. Binns, M. Bairley, and L.E. Green, Postal survey of ovine caseous lymphadenitis in the United Kingdom between 1990 and 1999, Vet. Rec., 150, , 2002, 263-268.

[40] P. Maximescu, A. Oprisan, A. Pop, and E. Potorac, Further studies on Corynebacterium species capable of producing diphtheria toxin (C. diphtheriae, C. ulcerans, C. ovis), J. General Microbiol., 82, 1974, 49-56.

[41] L.M. De Winter, K.A. Bernard, and M.G. Romney, Human clinical isolates of Corynebacterium diphtheriae and Corynebacterium ulcerans collected in Canada from 1999 to 2003 but not fitting reporting criteria for cases of diphtheria, J. Clin. Microbiol., 43, 2005, 3447-3449.

[42] K.S. Wagner, J.M. White, N.S. Crowcroft, G. Mann, and A. Efstratiou, Diphtheria in the United Kingdom, 1986-2008: the increasing role of Corynebacterium ulcerans, Epidemiol. Infect., 138, 2010, 1519-1530.

[43] M.E. Nairn, and J.P. Robertson, Corynebacterium pseudotuberculosis infection of sheep: role of skin lesions and dipping fluids, Aust. Vet. J., 50, 1974, 537--542.

[44] A.S. Guimarães, N. Seyffert, B.L. Bastos, et al., Caseous lymphadenitis in sheep flocks of the state of Minas Gerais, Brazil: prevalence and management surveys, Small Rumin. Res., 87, 2009, 86-91

[45] S. Rizvi, L.E. Green, and M.J. Glover, Caseous lymphadenitis: An increasing cause for concern, Vet. Rec., 140, $1997,586-587$. 
[46] A.R.A.R. Hamad, M.T.A. Shigidi, S.M. El-Sanousi, Abscess disease of sheep in the Sudan. Sudan J. Vet. Sci. Anim. Husb., 3, 1992, 60-61.

[47] M.N. Adza Rina, M. Zamri-Saad, F.F.A. Jesse, A.A. Saharee, A.W. Haron, and S. Shahirudin, Clinical and pathological changes in goats inoculated with Corynebacterium pseudotuberculosis by intradermal, intranasal and oral routes, Online J. Vet. Res., 17 (2), 2013, 73-83.

[48] T.C. Jones, R.D. Hunt, and N.W. King, Vet. pathol., 6 (Baltimore: Williams and Wilkins, 1997) 481-482

[49] R. Cruickshank, J.P. Duguid, B.P. Mariom, and R.H.A. Swain, Medical microbiology the practice of medical microbiology, 12 (London: Churchill Livingstone, 1975).

[50] K.M. Rodwan, Trials against Morel's disease vaccine in sheep, doctoral diss., University of Khartoum, Khartoum, 1996.

[51] D. Jones, and M.D. Collins, Irregular, nonsporing Gram positive rods, in P.H.A. Sneath, et al. (Ed.), Bergey’s manual of systematic bacteriology, 2 (Baltimore: Williams and Wilkins, 1986), 1261-1282.

[52] I.A. Merchant, and R.A. Packer, The Genus Corynebacterium, in Veterinary bacteriology and virology (Iowa: The Iowa State University Press).

[53] C.M. Cameron, and C.F. Swart, A new liquid medium for the cultivation of Corynebacterium pseudotuberculosis, J. S. Afr. Vet. Med. Ass., 36, 1965, 185-188.

[54] P.J. Quinn, M.E. Carter, B. Markey, and G.R. Carter, Corynebacterium species and Rhodococcus equi, in Clinical veterinary microbiology (London: Wolfe Publishing Company).

[55] C.A.,Muckle, and C.L. Gyles, Characterization of strains of Corynebacterium pseudotuberculosis, Can. J. Comp. Med., 46, 1982, 206-208.

[56] L.R.R. Costa, S.J. Spier, and D.C. Hirsh, Comparative molecular characterization of Corynebacterium pseudotuberculosis of different origin, Vet. Microbiol., 62, 1998, 135-143.

[57] S.S. Sutherland, R.A. Hart, and N.B. Buller, Genetic differences between nitrate negative and nitrate-positive Corynebacterium pseudotuberculosis strains using restriction fragment length polymorphisms, Vet Microbiol., 49, 1996, 1-9.

[58] M. Aynaud, and C. R. La botryomycose du mounton, Acad. Sci., 175, 1922, 1170-1172.

[59] O. Szalus-Jordanow, T. Kanbar, I. Soedarmanto, N. Eissa, J. Alber, C. Lämmler, M. Zschöck, R. Weiss, J. Kaba, and T. Frymus, Phenotypic and genotypic properties of Staphylococcus aureus subsp. anaerobius isolated from lymph node abscesses of goats, Berl. Munch. Tierarztl. Wochenschr., 124(3-4), 2011, 123-7.

[60] J.G. Songer, Bacterial phospholipases and their role in virulence, Trends Microbiol., 5, 1997, 156-160.

[61] J.J. Tashjian, and S.G. Campbell, Interaction between caprine macrophages and Corynebacterium pseudotuberculosis: an electron microscopy study, Am. J. Vet. Res., 44, 1983, 690-693.

[62] R.G. Batey, Pathogenesis of caseous lymphadenitis in sheep and goats, Aust. Vet. J., 63, 1986, $269-272$.

[63] S.J. Billington, P.A. Esmay, J.G. Songer, and B.H Jost, Identification and role in virulence of putative iron acquisition genes from Corynebacterium pseudotuberculosis, FEMS Microbiol. Lett., 208, 2002, 41-45.

[64] K.M. Connor, M.C. Fontaine, K. Rudge, et al., Molecular genotyping of multinational ovine and caprine Corynebacterium pseudotuberculosis isolates using pulsedfield gel electrophoresis, Vet. Res. 38, 2007, 613-623.

[65] I. Stefanska, M. Rzewuska, and M. Binek, Evaluation of three methods for DNA fingerprinting of Corynebacterium pseudotuberculosis strains isolated from goats in Poland, Polish J. Microbiol., 57, 2008, 105-112.

[66] H. Elbir, E.J. Feil, M. Drancourt, V. Roux, S.M. El Sanousi, M. Eshag, P. Colque-Navarro, I. Kühn, and J. Flock, Ovine clone ST1464: A predominant genotype of Staphylococcus aureus subsp. anaerobius isolated from sheep in Sudan, J. Infect. Dev. Ctries., 4(4), 2010, 235-238.

[67] T. J. Foster, The Staphylococcus aureus "superbug”, J. Clin. Invest., 114, 2004, 1693-1696.

[68] A.L. Cheung, A.S. Bayer, G. Zhang, H. Gresham, and Y.Q. Xiong, Regulation of virulence determinants in vitro and in vivo in Staphylococcus aureus, FEMS Immunol. Med. Microbiol., 40, 2004, 1-9.

[69] C.C. Brown, and H.J. Olander, Caseous lymphadenitis of goats and sheep: a review, Vet. Bull., 57, 1987, 1-11.

[70] A.A. Ismail, and Y.M.A. Hamid, Studies on the effect of some chemical disinfectants used in veterinary practice in Corynebacterium ovis, J. Egyptian Vet. Med. Assoc., 32, 1972, 195-202.

[71] C.C. Brown, H.J. Olander, and S.F. Alves, Synergistic hemolysis-inhibition titers associated with caseous lymphadenitis in a slaughterhouse survey of goats and sheep in Northeastern Brazil, Can. J. Vet. Res., 51, 1987, 46-49.

[72] M.G. Collett, G.F. Bath, and C.M. Cameron, Corynebacterium pseudotuberculosis infections, in J. Coetzer, and G.R. Thomson (Ed.), Infectious diseases of livestock with special reference to Southern Africa, 2 (Capetown: Oxford University Press, 1994) 1387-1395.

[73] M. Pépin, H.F. Seow, L. Corner, J.S. Rothel, A.L. Hodgson, et al., Cytokine gene expression in sheep following experimental infection with various strains of Corynebacterium pseudotuberculosis differing in virulence, Vet. Res., 28, $1997,149163$.

[74] M. I. Gómez, D. O. Sordelli, F. R. Buzzola, and V. E. García, Induction of cell-mediated immunity to Staphylococcus aureus in the mouse mammary gland by the local immunization with a live attenuated mutant, Infect. Immun., 70(8), 2002, 4254-4260.

[75] J.J. Pekelder, Caseous lymphadenitis, in W.B. Martin, and I.D. Aitken, Diseases of sheep, 3 (Oxford: Blackwell Science).

[76] M.T. Shigidi, An indirect haemagglutination test for the sero-diagnosis of Corynebacterium ovis infection in sheep, Res. Vet. Sci., 24, 1978, 57-60.

[77] G.J. Baird, and M.C. Fontaine, Corynebacterium pseudotuberculosis and its role in ovine caseous lymphadenitis, J. Comp. Pathol., 137, 2007, 179-210.

[78] J. Kaba, L. Kutschke, and G.F. Gerlach, Development of an ELISA for the diagnosis of Corynebacterium pseudotuberculosis infections in goats, Vet. Microbiol., 78, 2001, 155-163.

[79] N. Seyffert, A.S. Guimarães, L.G.C. Pacheco, R.W. Portela, B.L. Bastos, et al., High seroprevalence of caseous lymphadenitis in Brazilian goat herds revealed by Corynebacterium pseudotuberculosis secreted proteins-based ELISA, Res. Vet Sci., 88, 2010, 5055.

[80] L.G.C. Pacheco, R.R. Pena, T.L.P. Castro, F.A. Dorella, R.C. Bahia, et al., Multiplex PCR assay for identification of Corynebacterium pseudotuberculosis from pure cultures and for rapid detection of this pathogen in clinical samples, J. Med. Microbiol., 56, 2007, 480-486

[81] K. B. Al-Harbi, Bacterial isolates from visceral abscesses of sheep at Qassim, Saudi Arabia, Afric. J. of Microbiol. Res., 5(31), 2011b, 5622-5627.

[82] R. Carminati, R. Bahia, and L.F.M. Costa, et al., Determinação da sensibilidade e da especificidade de um teste de ELISA indireto para o diagnóstico de linfadenite caseosa em caprinos, R. Cienc. Méd. Biol., 2, 2003, 88-93.

[83] J.F, Prescott, P.I. Menzies, and Y.T. Hwang, An interferon gamma assay for diagnosis of Corynebacterium pseudotuberculosis infection in adult sheep from a research flock, Vet. Microbiol., 88, 2002, 287-297. 
[84] P.I. Menzies, Y. Hwang, and J.F. Prescott, Comparison of an interferon- $\gamma$ to a phospholipase D enzyme-linked immunosorbent assay for diagnosis of Corynebacterium pseudotuberculosis infection in experimentally infected goats, Vet. Microbiol., 100, 2004, 129-137.

[85] V. Sunil, P.I. Menzies, P.E. Shewen, J.F. Prescott, Performance of a whole blood interferon-gamma assay for detection and eradication of caseous lymphadenitis in sheep, Vet. Microbiol., 30, 2008, 288-297.

[86] K. B. Al-Harbi, Control of abscess disease of sheep by concurrent vaccination, zinc injection and antiseptic washing, Res. J. Vet. Sci., 4 (1), 2011c, 9-13.

[87] C.N. Nozaki, M.A.R, Faria, and T.M.M. Machado, Extirpação cirúrgica dos abscessos da linfadenite caseosa em caprinos, Arq. Inst. Biol., 67, 2000, 187-189.

[88] M.E. Olson, H. Ceri, D.W. Morck, et al., Biofilm bacteria: formation and comparative susceptibility to antibiotics, Can. J. Vet. Res., 66, 2002, 86-92.

[89] S.G. Campbell, M.K. Ashfaq, and J.J. Tashjian, Caseous lymphadenitis in goats in the USA, in Proceedings $3^{\text {rd }}$ international conference on goat production and disease (Tucson: Arizona, 1982) 449-454.

[90] M. Pépin, P. Pardon, J. Marly, F. Lantier, and J.L. Arrigo, Acquired immunity after primary caseous lymphadenitis in sheep, Am. J. Vet. Res., 54, 1993, 873-877.

[91] K. Stanford, K.A. Brogden, L.A. McClelland, G.C. Kozub, and F. Audibert, The incidence of caseous lymphadenitis in Alberta sheep and assessment of impact by vaccination with commercial and experimental vaccines, Can. J. Vet. Res., 1, 1998, 38-43.

[92] K.A. Brogden, J.S. Glenn, N. East, and F.A. Audibert, Corynebacterium pseudotuberculosis bacterin with muramyl dipeptide induces antibody titers, increases the time of onset, and decreases naturally occurring external abscesses in sheep and goats, Small Rumin. Res., 19, 1996, 161-168.

[93] C.C. Brown, H.J. Olander, E.L. Biberstein, and S.M. Morse, Use of a toxoid vaccine to protect goats against intradermal challenge exposure to Corynebacterium pseudotuberculosis, Am. J. Vet. Res., 47, 1986, 1116-1119.

[94] D.G. Eggleton, H.D. Middleton, C.V. Doidge, and D.W. Minty, Immunisation against ovine caseous lymphadenitis: comparison of Corynebacterium pseudotuberculosis vaccines with and without bacterial cells, Aust. Vet. J., 68, 1991, 317-319.

[95] M.C. Fontaine, G. Baird, K.M. Connor, K. Rudge, J. Sales, et al., Vaccination confers significant protection of sheep against infection with a virulent United Kingdom strain of Corynebacterium pseudotuberculosis, Vaccine, 24, 2006, 5986-5996.

[96] J. Walker, I.H.J. Jackson, D.G. Eggleton, E.N.T. Meeusen, and M.J. Wilson, Identification of a novel antigen from Corynebacterium pseudotuberculosis that protects sheep against caseous lymphadenitis, Infect. Immun., 62, 1994, $2562-2567$.

[97] W.U. Braga, Protection in alpacas against Corynebacterium pseudotuberculosis using different bacterial components, Vet. Microbiol., 119, 2007, 297-303.

[98] M.I. El-Enbaawy, M.M. Saad, and S.A. Selim, Humoral and cellular immune responses of a murine model against Corynebacterium pseudotuberculosis antigens, Egyptian J. Immun., 12, 2005, 13-20.

[99] C.P. Simmons, A.L.M. Hodgson, R.A. Strugnell, Attenuation and vaccine potential of aroQ mutants of Corynebacterium pseudotuberculosis, Infect. Immun., 65, 1997, 3048-3056.

[100] D.T. Lan, S. Taniguchi, S. Makino, T. Shirahata, and A. Nakane, Role of endogenous tumor necrosis factor alpha and gamma interferon in resistance to Corynebacterium pseudotuberculosis infection in mice, Microbiol. Immunol., 42, 1998, 863-870.

[101] A.L.M. Hodgson, M. Tachedjian, L.A. Corner, et al., Protection of sheep against caseous lymphadenitis by use of a single oral dose of live recombinant Corynebacterium pseudotuberculosis, Infec. Immun., 62, 1994, 5275-5280.

[102] C.P. Simmons, S.J. Dunstan, M. Tachedjian, et al., Vaccine potential of attenuated mutants of Corynebacterium pseudotuberculosis, Infect. Immun., 66, 1998, 474-479.

[103] R. Meyer, R. Carminati, R.C. Bahia, V.L. Vale, and S. Viegas, et al., Evaluation of the goats humoral immune response induced by the Corynebacterium pseudotuberculosis lyophilized live vaccine, Med. Biol. Sci. J., 1, 2002, $42-48$.

[104] L.F. Moura-Costa, R.C. Bahia, R. Carminati, V.L. Vale, B.J. Paule, et al., Evaluation of the humoral and cellular immune response to different antigens of Corynebacterium pseudotuberculosis in Canindé goats and their potential protection against caseous lymphadenitis, Vet. Immunol. Immunopathol., 126, 2008, 131-141.

[105] K. Rodwan, A. Babiker, and S. El Sanousi, Studies on vaccination trials against Morel's disease and monitoring of transfer of passive immunity from dams to lambs, Deutscher tropentag abstracts, Berlin, 2004.

[106] O.M. Mahmoud, E.M. Haroun, and O.H. Omer, The effect of zinc injection on the duration of protection against abscess diseases in vaccinated ewes, Res. J. Vet. Sci., 2, 2009, 10-13.

[107] O.M. Mahmoud, F. Elsamani, and A.O. Bakheit, Zinc deficiency in Sudanese desert sheep, J. Comp. Pathol., 93, 1983, 591-595. 